\title{
The Endogenous Cannabinoid 2-Arachidonoylglycerol Is Intravenously Self-Administered by Squirrel Monkeys
}

\author{
Zuzana Justinová, ${ }^{1,2}$ Sevil Yasar, ${ }^{3}$ Godfrey H. Redhi, ${ }^{1}$ and Steven R. Goldberg ${ }^{1}$ \\ ${ }^{1}$ Preclinical Pharmacology Section, Behavioral Neuroscience Research Branch, Intramural Research Program, National Institute on Drug Abuse, National \\ Institutes of Health, Department of Health and Human Services, Baltimore, Maryland 21224, ${ }^{2}$ Maryland Psychiatric Research Centre, Department of \\ Psychiatry, University of Maryland School of Medicine, Baltimore, Maryland 21228, and '3ivision of Geriatric Medicine and Gerontology, Department of \\ Medicine, Johns Hopkins University School of Medicine, Baltimore, Maryland 21224
}

Two endogenous ligands for cannabinoid $\mathrm{CB}_{1}$ receptors, anandamide ( $N$-arachidonoylethanolamine) and 2 -arachidonoylglycerol (2-AG), have been identified and characterized. 2-AG is the most prevalent endogenous cannabinoid ligand in the brain, and electrophysiological studies suggest 2-AG, rather than anandamide, is the true natural ligand for cannabinoid receptors and the key endocannabinoid involved in retrograde signaling in the brain. Here, we evaluated intravenously administered 2-AG for reinforcing effects in nonhuman primates. Squirrel monkeys that previously self-administered anandamide or nicotine under a fixed-ratio schedule with a $60 \mathrm{~s}$ timeout after each injection had their self-administration behavior extinguished by vehicle substitution and were then given the opportunity to self-administer 2-AG. Intravenous 2-AG was a very effective reinforcer of drug-taking behavior, maintaining higher numbers of self-administered injections per session and higher rates of responding than vehicle across a wide range of doses. To assess involvement of $\mathrm{CB}_{1}$ receptors in the reinforcing effects of 2-AG, we pretreated monkeys with the cannabinoid $\mathrm{CB}_{1}$ receptor inverse agonist/antagonist rimonabant [N-piperidino-5-(4-chlorophenyl)-1-(2,4dichlorophenyl)-4-methylpyrazole-3-carboxamide]. Rimonabant produced persistent blockade of 2-AG self-administration without affecting responding maintained by food under similar conditions. Thus, 2-AG was actively self-administered by monkeys with or without a history of cannabinoid self-administration, and the reinforcing effects of $2-\mathrm{AG}$ were mediated by $\mathrm{CB}_{1}$ receptors. Self-administration of 2-AG by squirrel monkeys provides a valuable procedure for studying abuse liability of medications that interfere with 2-AG signaling within the brain and for investigating mechanisms involved in the reinforcing effects of endocannabinoids.

\section{Introduction}

Endocannabinoids are essential modulators of synaptic transmission throughout the CNS. Following release from postsynaptic neurons, endocannabinoids travel through the synaptic cleft to engage presynaptic cannabinoid $\mathrm{CB}_{1}$ receptors. The outcome of this retrograde signaling is a decrease in synaptic transmission and short- or long-term synaptic modulation (Katona and Freund, 2008). 2-Arachidonoylglycerol (2-AG) was the second endogenous cannabinoid receptor ligand discovered after anandamide ( $\mathrm{N}$-arachidonoylethanolamine) (Mechoulam et al., 1995; Sugiura et al., 1995), but anandamide has been far more extensively studied. Both 2-AG and anandamide are ligands for cannabinoid receptors $\left(\mathrm{CB}_{1}\right.$ and $\left.\mathrm{CB}_{2}\right)$, but there are many differences between them. Levels of 2-AG in the brain are higher than those of anandamide, and this difference appears similar in non-

\footnotetext{
Received Nov. 19, 2010; revised March 3, 2011; accepted March 10, 2011.

Author contributions: Z.J., S.Y., and S.R.G. designed research; G.H.R. performed research; Z.J. analyzed data; Z.J. and S.R.G. wrote the paper.

This work was supported by the Intramural Research Program of the National Institute on Drug Abuse, National Institutes of Health, Department of Health and Human Services.

The authors declare no competing financial interests.

Correspondence should be addressed to Dr. Steven R. Goldberg, Preclinical Pharmacology Section, NIDA, IRP, NIH,

251 Bayview Boulevard, Baltimore, MD 21224. E-mail: sgoldber@mail.nih.gov.

DOI:10.1523/JNEUROSCI.6058-10.2011

Copyright $\odot 2011$ the authors $\quad 0270-6474 / 11 / 317043-06 \$ 15.00 / 0$
}

human primate and rodent brains (1000-fold vs 800 -fold difference, respectively) (Sugiura et al., 1995; Justinova et al., 2008), but lower differences ( $\sim 200$-fold difference) in rodent brain were also reported (Bisogno et al., 1999). Although anandamide binds to cannabinoid receptors with a higher affinity than 2-AG, it acts only as a partial agonist (Mackie et al., 1993), while 2-AG acts as a full agonist at these receptors (Gonsiorek et al., 2000; Savinainen et al., 2001). Also, 2-AG selectively binds to cannabinoid receptors, while anandamide also interacts with noncannabinoid binding sites such as vanilloid receptors (for review, see Pertwee, 2008). Based on these differences between 2-AG and anandamide, and on recent electrophysiology and anatomical studies, it has been proposed that 2-AG, rather than anandamide, is the true natural ligand for cannabinoid receptors and the key endocannabinoid involved in retrograde signaling in the brain (Sugiura et al., 2006; Katona and Freund, 2008; Tanimura et al., 2010).

Drugs of abuse affect central levels of 2-AG differently, depending on the abused drug, the brain area studied, and the methodology used. There is strong evidence for endocannabinoid involvement in the rewarding effects of $\Delta^{9}$-tetrahydrocannabinol (THC) (Di Marzo et al., 2000), and ethanol and opiates (Viganò et al., 2003; Caillé et al., 2007), as opposed to psychostimulants such as cocaine (González et al., 2002; Caillé et al., 2007). Although 2-AG is the most prevalent endogenous cannabinoid receptor ligand in the brain and appears to be involved in the 
rewarding effects of many abused drugs, its reinforcing effects have not yet been assessed in an animal model of drug abuse.

We previously demonstrated that anandamide, like THC, serves as an effective reinforcer of drug self-administration behavior in squirrel monkeys when injected intravenously (Justinova et al., 2005). Here, we studied the reinforcing effects of intravenously self-administered $2-A G$ using the same squirrel monkey model. We used monkeys with a history of anandamide selfadministration, as well as monkeys with a history of nicotine self-administration. We also evaluated whether cannabinoid $\mathrm{CB}_{1}$ receptors mediated any reinforcing effects of 2-AG observed by pretreating monkeys responding for intravenous injections of 2-AG (and, for comparison, monkeys responding for THC or food under the same conditions) with the cannabinoid $\mathrm{CB}_{1}$ receptor inverse agonist/antagonist rimonabant [ $N$-piperidino-5-(4-chlorophenyl)-1-(2,4-dichlorophenyl)-4-methylpyrazole-3-carboxamide] before experimental sessions.

\section{Materials and Methods}

Animals. Seventeen adult male squirrel monkeys (Saimiri sciureus) weighing $0.75-1.15 \mathrm{~kg}$ were housed in individual cages in a temperature- and humidity-controlled room with unrestricted access to water. Monkeys were fed ( $\sim 2 \mathrm{~h}$ after the session) a daily ration of five biscuits of high-protein monkey diet (Lab Diet 5045, PMI Nutrition International) and two pieces of Banana Softies (Bioserv), which maintained body weights at a constant level throughout the study. Fresh fruits, vegetables, and environmental enrichment were provided daily. Animals were maintained in facilities fully accredited by the Association for Assessment and Accreditation of Laboratory Animal Care International, and experiments were conducted in accordance with guidelines of the Institutional Animal Care and Use Committee of the Intramural Research Program, National Institute on Drug Abuse (NIDA), National Institutes of Health, Department of Health and Human Services.

Two groups of four monkeys each were used for experiments with 2-AG, as follows: an anandamide group (monkeys 70F4, 67F4, 42A, and $6754)$ that had prior experience with self-administration of anandamide and anandamide reuptake inhibitors (AM404 and VDM11); and a nicotine group (monkeys 577, 431, 441, and 572) that had prior experience with self-administration of nicotine. A third group of five animals that had experience with self-administration of THC was used to test rimonabant in monkeys (monkeys 66B2, 453, 434, 25B, and 37B). A fourth group of four monkeys was used to study the effects of rimonabant on responding reinforced by food (monkeys 34A, 27B, 30A, and 1549).

Apparatus. Experimental chambers and other apparatus used in this study were the same as previously described in detail (Justinova et al., 2003). Monkeys were surgically prepared with chronic indwelling venous catheters (polyvinyl chloride) and wore nylon-mesh jackets to protect the catheters. The monkey's catheter was connected to polyethylene tubing, which passed out of the isolation chamber where it was attached to a motor-driven syringe pump. Before the start of each session, monkeys were placed into the Plexiglas chairs and restrained in the seated position by waist locks.

Self-administration procedure. One hour sessions were conducted $5 \mathrm{~d}$ per week (typically Monday to Friday). Before the start of each session, catheters were flushed with $1 \mathrm{ml}$ of saline, and one priming injection was delivered (calculated to fill the dead space of the IV catheter). At the start of the session, a white house light was turned off and green stimulus lights were turned on. In the presence of the green lights, monkeys were required to make 10 responses on a lever [ 10 response, fixed-ratio schedule of reinforcement (FR10)] to produce an injection of anandamide. The completion of 10 responses on the lever turned off the green lights and produced an intravenous injection of $30 \mu \mathrm{g} / \mathrm{kg}$ anandamide paired with a 2 s illumination of amber stimulus lights. The duration of each injection was $0.2 \mathrm{~s}$, and the injection volume was $0.2 \mathrm{ml}$. Each injection was followed by a $60 \mathrm{~s}$ timeout period, during which the chamber was dark and lever presses had no programmed consequences. The same schedule and conditions were used in groups of monkeys that had learned to respond for injections of nicotine ( $30 \mu \mathrm{g} / \mathrm{kg}$ ) or THC ( $4 \mu \mathrm{g} / \mathrm{kg})$, or for delivery of food (190 mg banana-flavored food pellets; F0035, Bioserv).

When the responding for $30 \mu \mathrm{g} / \mathrm{kg}$ injections of anandamide or nicotine was stable for at least five consecutive sessions ( $<15 \%$ variability), self-administration behavior was extinguished by replacing anandamide or nicotine with its vehicle for five consecutive sessions, followed by replacement of vehicle with $3 \mu \mathrm{g} / \mathrm{kg}$ injections of $2-\mathrm{AG}$ for five sessions. Then, in the anandamide-experienced monkeys, a 2-AG dose-effect curve was constructed by giving monkeys the opportunity to selfadminister a range of $2-A G$ doses $(0.1,0.3,1,3,10,30$, and $100 \mu \mathrm{g} / \mathrm{kg} /$ injection). Each 2-AG dose was studied for four to five consecutive sessions, and each dose-condition was separated by four to five consecutive sessions of vehicle extinction. Afterward we studied the effects of $5 \mathrm{~d}$ presession treatment with $0.3 \mathrm{mg} / \mathrm{kg}$ rimonabant or its vehicle (given intramuscularly, $60 \mathrm{~min}$ before session) on self-administration of the 3 $\mu \mathrm{g} / \mathrm{kg}$ dose of 2-AG (a dose that maintained maximum rates of responding). The effects of vehicle or rimonabant $(0.3 \mathrm{mg} / \mathrm{kg})$ for five sessions were also determined in a group of monkeys responding for a $4 \mu \mathrm{g} / \mathrm{kg}$ THC injections (a dose of THC that maintains maximum rates of responding under these schedule conditions) and in a group of monkeys responding for food pellets under the same FR10 schedule of reinforcement. All monkeys were injected with vehicle or rimonabant in the chair and were then returned to their home cage until the start of the experimental session.

The monkeys used in the current study had extensive experience with vehicle extinction before the present experiments, including repeated epi- 

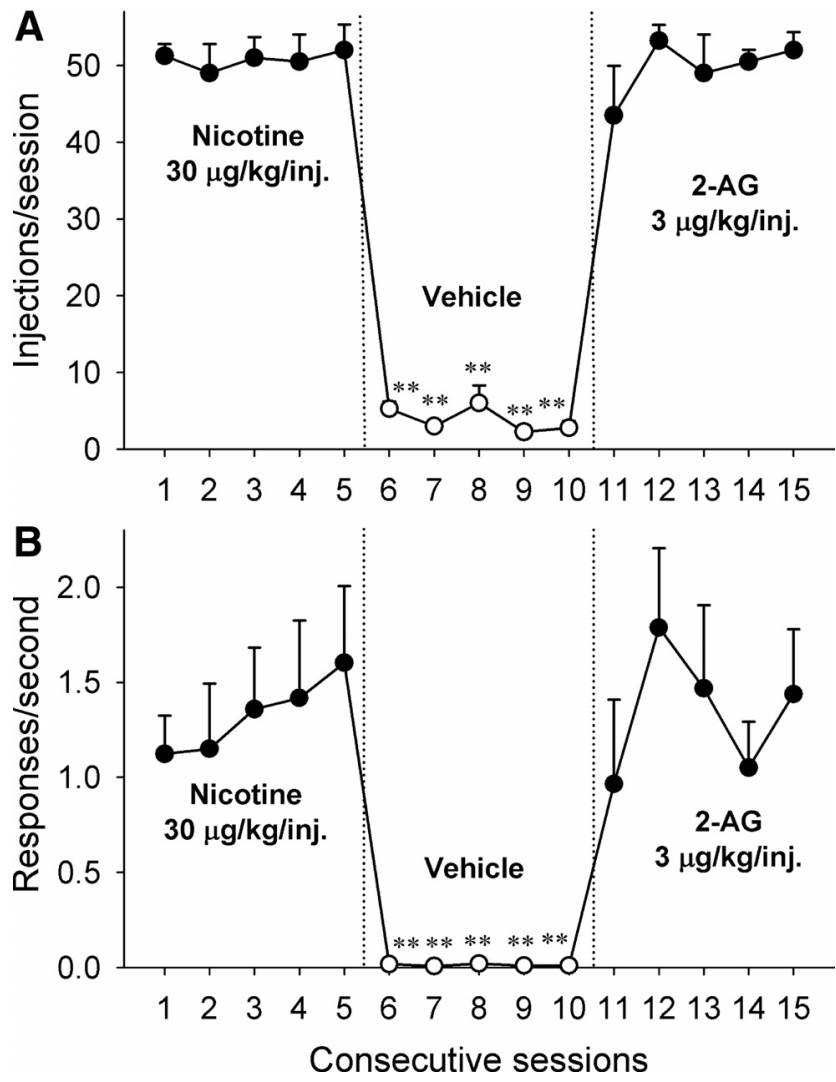

Figure 2. 2-AG self-administration in nicotine-experienced monkeys over consecutive sessions. $\boldsymbol{A}, \boldsymbol{B}$, Number of injections per session $(\boldsymbol{A})$ and overall rates of responding $(\boldsymbol{B})$ in the presence of a green light during $30 \mu \mathrm{g} / \mathrm{kg} /$ injection nicotine sessions (sessions $1-5$, closed circles), vehicle sessions (sessions 6-10, open circles), and 2-AG $3 \mu \mathrm{g} / \mathrm{kg} /$ injection sessions (sessions 11-15, closed circles) are shown. Points represent means \pm SEM from four subjects. ${ }^{* *} p<0.01$, post hoc comparisons with the last session before vehicle extinction (session 5).
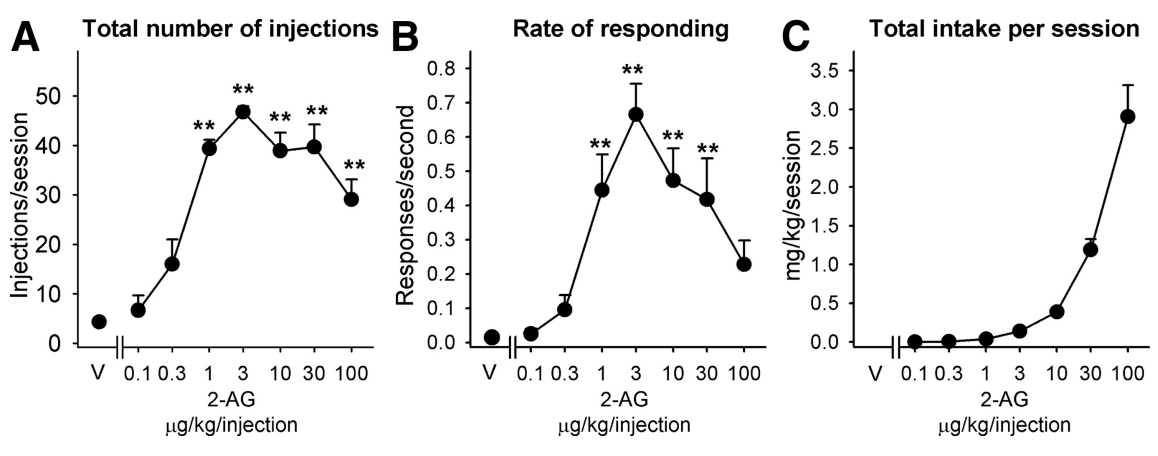

Figure 3. Effects of varying injection dose on self-administration of 2-AG. $\boldsymbol{A}-\boldsymbol{C}$, Number of injections of 2-AG per session $(\boldsymbol{A})$, overall rates of responding in the presence of the green light signaling 2-AG availability $(\boldsymbol{B})$, and total 2-AG intake per session $(\boldsymbol{C})$ are shown as a function of injection dose of drug. Each point represents the mean \pm SEM $(n=4)$ of the last three sessions under each 2-AG unit dose condition and under a vehicle condition. ${ }^{* *} p<0.01$ post hoc comparisons with the vehicle conditions. V, Vehicle. during time-outs not included in calculations. Data for dose-effect curves are expressed as mean response rates and numbers of reinforcements per session \pm SEM over the last three sessions. In addition, total intake of 2-AG for each dose was calculated. Effects of pretreatment with rimonabant on drug and food self-administration, as well as extinction and acquisition data, are expressed as mean \pm SEM of total numbers of reinforcements per session and rates of responding as a function of consecutive daily self-administration sessions. For statistical evaluation of effects of rimonabant or vehicle extinction over consecutive sessions, the last session of vehicle pretreatment was used as a control value to allow comparisons with subsequent sessions during pretreatment or extinction. For statistical evaluation of recovery of the behavior from extinction or rimonabant pretreatment over consecutive sessions, the last session of extinction or pretreatment was used as a control value to allow comparisons with subsequent sessions. Statistical analysis (SigmaStat, Jandel Scientific) was performed using single-factor repeated-measures ANOVA to assess differences between vehicle and test drug pretreatment conditions or between different doses of 2-AG and vehicle. Significant main effects were analyzed further by subsequent paired comparisons to control values using Dunnett's test. Differences were considered statistically significant at $p<0.05$.

Drugs. 2-AG was provided by NIDA Research Resources Drug Supply Program and was dissolved in a vehicle containing 5\% ethanol, 3\% Tween 80 , and sterile water to obtain a stock solution with a concentration of $1.5 \mathrm{mg} / \mathrm{ml}$, which was further diluted with sterile water as needed. Anandamide (synthesized in the laboratory of Dr. Alexandros Makriyannis at the Centre for Drug Discovery, Northeastern University, Boston, MA) and $\Delta^{9}$-THC (NIDA Research Resources Drug Supply Program, Bethesda) were dissolved in a vehicle containing $1 \%$ ethanol, $1 \%$ Tween 80, and saline. Rimonabant (SR141716, provided by NIDA Research Resources Drug Supply Program) was dissolved in a vehicle of $2 \%$ ethanol, $2 \%$ Tween 80 , and sterile water.

\section{Results}

Extinction of anandamide self-administration and acquisition of 2-AG self-administration

The monkeys learned to press a lever for intravenous injections of $30 \mu \mathrm{g} / \mathrm{kg}$ anandamide (FR10 schedule) during $1 \mathrm{~h}$ daily sessions. Injections of $30 \mu \mathrm{g} / \mathrm{kg}$ anandamide maintained high response rates (mean, $0.68 \pm 0.11 \mathrm{response} / \mathrm{s}$ ) and high numbers of self-administered injections each session (mean, $47.08 \pm 1.73$ injections/session). When vehicle injections were substituted for anandamide injections, rates of responding $\left(F_{(5,15)}=50.05, p<\right.$ $0.001)$, as well as the number of injections self-administered per session $\left(F_{(5,15)}=\right.$ 41.65, $p<0.001)$, decreased dramatically (Fig. $1 A, B$ ). When vehicle injections were replaced with $3 \mu \mathrm{g} / \mathrm{kg}$ injections of $2-\mathrm{AG}$, self-administration behavior immediately recovered; thus, acquisition of 2-AG selfadministration was very rapid (injections: $F_{(5,15)}=27.06, p<0.001$; rates: $F_{(5,15)}=$ $5.20, p=0.006)($ Fig. 1A,B). sodes of extinction during initial acquisition of baseline self-administration behavior. As a result, self-administration behavior ceased virtually immediately when vehicle is injected during the session in these monkeys. We have observed a gradual fall-off during the first several extinction periods during initial acquisition of anandamide, THC, or nicotine self-administration behavior, but this disappears with repeated extinction experience.

Data analysis. Cumulative response records were obtained during all sessions to assess within-session patterns of responding. The number of reinforcements (injections or pellets) per session represent total number of injections delivered per session. The rates of responding are expressed as responses per second averaged over the $1 \mathrm{~h}$ session, with responding

\section{Extinction and reacquisition of 2-AG self-administration}

During construction of a dose-response curve for 2-AG, vehicle extinction always preceded and followed testing of each dose of 2-AG. Substitution of vehicle for 2-AG $(30 \mu \mathrm{g} / \mathrm{kg} /$ injection shown in Fig. $1 C, D)$ caused a significant decline in the number of injections delivered per session (Fig. 1C) $\left(F_{(4,12)}=193.30, p<\right.$ $0.001)$ and in the rates of responding (Fig. $1 D)\left(F_{(4,12)}=27.02\right.$, $p<0.001)$. Replacement of vehicle injections with injections of $2-\mathrm{AG}(1 \mu \mathrm{g} / \mathrm{kg} /$ injection shown in Fig. $1 C, D)$ resulted in imme- 
diate recovery of drug-taking behavior (injections: $F_{(4,11)}=$ $18.17, p<0.001$; rates: $\left.F_{(4,11)}=5.31, p=0.012\right)($ Fig. $1 C, D)$.

\section{2-AG self-administration in nicotine-experienced monkeys}

In a separate group of monkeys, we tested whether 2-AG is selfadministered by monkeys without a history of cannabinoid selfadministration. The monkeys learned to press a lever for intravenous injections of $30 \mu \mathrm{g} / \mathrm{kg}$ nicotine (FR10 schedule) during $1 \mathrm{~h}$ daily sessions. Injections of $30 \mu \mathrm{g} / \mathrm{kg}$ nicotine maintained high response rates (mean, $1.46 \pm 0.36$ responses/s) and high numbers of selfadministered injections each session (mean, $51.17 \pm 3.17$ injections/ session). When vehicle was substituted for nicotine, the rates of responding $\left(F_{(5,15)}=15.54, p<0.001\right)$, as well as the number of injections self-administered per session $\left(F_{(5,15)}=112.76, p<0.001\right)$, decreased dramatically (Fig. $2 A, B$ ). When vehicle injections were replaced with $3 \mu \mathrm{g} / \mathrm{kg}$ injections of $2-\mathrm{AG}$, self-administration behavior immediately recovered, and $2-A G$ was self-administered by nicotine-experienced monkeys similarly to anandamideexperienced monkeys (injections: $F_{(5,15)}=41.97, p<0.001$; rates: $\left.F_{(5,15)}=8.00, p<0.001\right)($ Fig. $2 A, B)$.

\section{Self-administration of 2-AG}

Varying the injection dose of 2-AG resulted in a classic invertedU-shape dose-effect curve. 2-AG maintained significantly higher rates of responding $\left(F_{(7,21)}=10.42, p<0.001\right)$ (Fig. $\left.3 B\right)$ and higher numbers of injections per session $\left(F_{(7,21)}=28.25, p<\right.$ 0.001 ) (Fig. 3A) than vehicle at doses 1, 3, 10, and $30 \mu \mathrm{g} / \mathrm{kg} /$ injection. The maximal rate of responding $(0.67 \pm 0.09$ response/s) and the number of injections per session (46.75 \pm 1.19 injections/session) were maintained by $3 \mu \mathrm{g} / \mathrm{kg} 2-A G$ per injection. The highest 2-AG intake per session was reached at a dose of $100 \mu \mathrm{g} / \mathrm{kg} /$ injection $(2.91 \pm 0.40 \mathrm{mg} / \mathrm{session})$ (Fig. 3C).

Effects of cannabinoid $\mathrm{CB}_{1}$ receptor blockade on responding maintained by $2-\mathrm{AG}, \mathrm{THC}$, and food pellets

Rimonabant at a dose of $0.3 \mathrm{mg} / \mathrm{kg}$ decreased the number of self-administered injections of 2-AG (Fig. $4 A)\left(F_{(5,10)}=7.96, p=\right.$ $0.003)$ and THC (Fig. $4 B)\left(F_{(5,20)}=34.66, p<0.001\right)$ to vehicle control levels within a few sessions. Overall rates of responding were also significantly decreased during the $5 \mathrm{~d}$ treatment with rimonabant (data not shown; 2-AG: $F_{(5,10)}=7.01, p=0.005$; THC: $\left.F_{(5,20)}=35.25, p<0.001\right) .2-A G$ self-administration rapidly recovered when rimonabant treatment was stopped (2-AG: injections: $F_{(3,6)}=51.77, p<0.001$; rates: $F_{(3,6)}=9.55, p=0.011$; THC: injections: $F_{(3,12)}=26.70, p<0.001$; rates: $F_{(3,12)}=13.50$, $p=0.011)$. Rimonabant at a dose $0.3 \mathrm{mg} / \mathrm{kg}$ did not alter responding maintained by food (Fig. $4 C$ ) (reinforcements: $F_{(3,15)}=$ $0.46, p=0.80$, rates, data not shown: $\left.F_{(3,15)}=0.61, p=0.69\right)$.

\section{Discussion}

Using an intravenous drug self-administration model in squirrel monkeys, we found that 2-AG, like THC, cocaine, and other abused drugs, was an effective reinforcer of drug-taking behavior. 2-AG was self-administered by monkeys that had a cannabinoid self-administration history (anandamide monkeys), as well as by monkeys with no history of cannabinoid self-administration (nicotine monkeys). The fact that 2-AG maintained drug-taking behavior in monkeys without a cannabinoid self-administration history suggests that the reinforcing effects of 2-AG were not dependent on prior self-administration of a particular class of drugs. Rates of responding maintained by $2-A G$ injections were comparable to those maintained under the same conditions by THC, anandamide, methanandamide (a metabolism-resistant
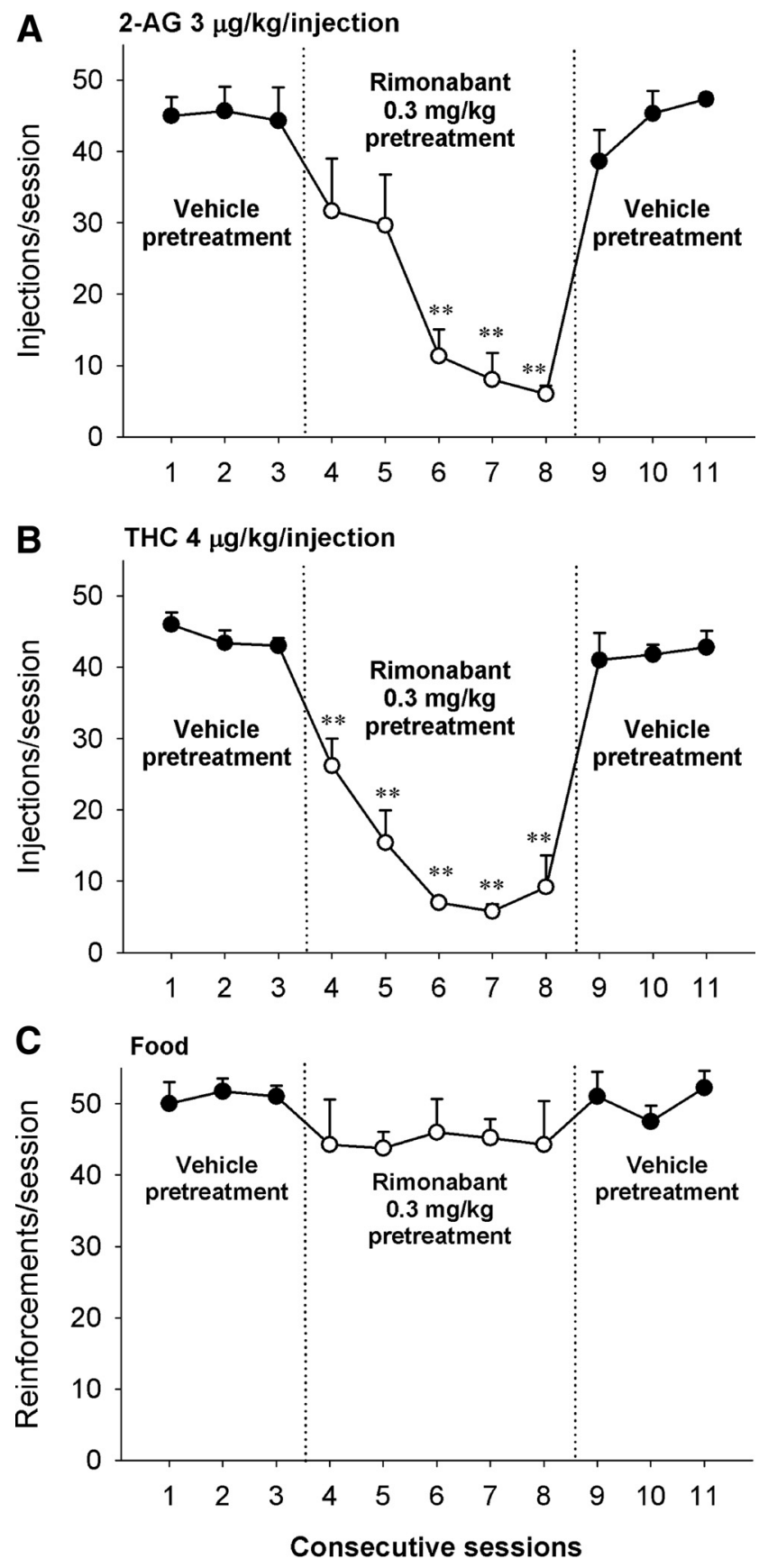

Figure 4. Effects of rimonabant given as a pretreatment before experimental session on responding maintained by 2-AG $(\boldsymbol{A})$, $\operatorname{THC}(\boldsymbol{B})$, or food $(\boldsymbol{C})$ during five consecutive sessions. $\boldsymbol{A}-\boldsymbol{C}$, Numbers of injections per session after intramuscular pretreatment with vehicle (sessions 1-3 and 9-11, closed circles,) or $0.3 \mathrm{mg} / \mathrm{kg}$ rimonabant (sessions 4-8, open circles) are shown. Each point represents the mean \pm SEM from three $(\boldsymbol{A})$, five $(\boldsymbol{B})$, or four $(\boldsymbol{C})$ monkeys. ${ }^{* *} p<$ 0.01 , post hoc comparisons with the last session with vehicle pretreatment (session 3 ) before pretreatment with rimonabant.

analog of anandamide), or cocaine injections in our previous studies (Tanda et al., 2000; Justinova et al., 2003, 2005, 2008).

Although the rates of responding maintained by $2-A G$ injections were comparable to those maintained under the same conditions by other cannabinoid or noncannabinoid drugs in our previous studies, 2-AG maintained very high levels of drugtaking behavior across a wider range of doses (1-30 $\mu \mathrm{g} / \mathrm{kg} / \mathrm{injec}-$ tion) than is typical for other cannabinoid or noncannabinoid drugs. For example, compared with a 30-fold difference between 
the highest and lowest dose in the effective dose range for 2-AG, there was only a 4 -fold difference between the highest and lowest dose in the effective dose range for THC (1-4 $\mu \mathrm{g} / \mathrm{kg} /$ injection), anandamide $(10-40 \mu \mathrm{g} / \mathrm{kg} /$ injection), and methanandamide $(10-40 \mu \mathrm{g} / \mathrm{kg} /$ injection $)$ in our previous self-administration studies (Tanda et al., 2000; Justinova et al., 2003, 2005). This may be explained by a combination of a very rapid metabolism of exogenously administered 2-AG in the brain and the full efficacy of 2-AG at cannabinoid $\mathrm{CB}_{1}$ receptors (Beltramo and Piomelli, 2000; Savinainen et al., 2001). It has been shown that a short duration of effects favors demonstration of a high frequency of self-administered injections under FR10 self-administration procedures (Ko et al., 2002). Thus, high potency and full efficacy at $\mathrm{CB}_{1}$ receptors may allow 2-AG to function as a robust reinforcer at a very low dose $(1 \mu \mathrm{g} / \mathrm{kg} /$ injection $)$, while rapid degradation restricts the accumulation of 2-AG in the brain with repeated injections over the session, and, thus, delays the consequent drop in the rates of responding and frequency of injection characteristic of the descending limb of the dose-response curve for most self-administered drugs and allows 2-AG to be an effective reinforcer at higher doses (up to $30 \mu \mathrm{g} / \mathrm{kg} /$ injection). Other cannabinoids acting as effective reinforcers of self-administration behavior do not exhibit this combination of pharmacokinetic and pharmacodynamic attributes. They are either rapidly metabolized in the brain, but have a lower efficacy (anandamide), or their metabolism is much slower than that of 2-AG (THC and methanandamide) (Agurell et al., 1986; Abadji et al., 1994).

The reinforcing effects of 2-AG in squirrel monkeys appear to be mediated by cannabinoid $\mathrm{CB}_{1}$ receptors, since daily presession treatment with rimonabant resulted in complete blockade of 2-AG self-administration behavior. Rimonabant produced a similar complete blockade of THC self-administration behavior in the present study and has been shown to block reinforcing effects of THC, as well as anandamide and methanandamide, but not cocaine, in previous studies with squirrel monkeys under the same schedule conditions (Tanda et al., 2000; Justinova et al., 2005). The gradual fall-off in 2-AG self-administration during the $5 \mathrm{~d}$ rimonabant regimen argues for antagonism of the 2-AG effects rather than a nonspecific reduction in rates of responding. Moreover, in the present study, rimonabant did not depress responding for food under the same schedule conditions used with 2-AG, so it is unlikely that the effects of rimonabant on 2-AG self-administration behavior were due to nonspecific depressant effects.

Anandamide and 2-AG are implicated in the pathophysiology of pain and anxiety, as well as many neuropsychiatric disorders, including Alzheimer's disease, multiple sclerosis, and addiction. It is therefore understandable that there is a wide interest in developing medications that promote the actions of both anandamide and 2-AG throughout the brain (e.g., by inhibiting their membrane transport or their metabolism) (for review, see Piomelli, 2005; Petrosino and Di Marzo, 2010). Since endogenously released cannabinoids can activate brain reward processes via $\mathrm{CB}_{1}$ receptors, which could lead to unwanted psychological side effects and eventually to drug abuse and addiction, there has been concern about abuse liability of potential therapeutics that enhance actions of endogenously released endocannabinoids, such as inhibitors of the primary anandamide-degrading enzyme fatty acid amide hydrolase (FAAH). Recent experiments in squirrel monkeys and rats have failed to find abuse-related rewarding or relapse-inducing effects with the most frequently studied FAAH inhibitor URB597 (Justinova et al., 2008.; Scherma et al., 2008), but newer FAAH inhibitors remain to be studied. The questions regarding the abuse liability of FAAH inhibitors are now being asked about recently developed inhibitors of the primary 2-AGdegrading enzyme monoacylglycerol lipase (MAGL) (Dinh et al., 2002; Minkkilä et al., 2010). Emerging evidence from rodent studies is showing that there are fundamental differences in the mode of signaling for the anandamide and 2-AG signaling pathways (Schlosburg et al., 2010), but also that these two major endocannabinoid pathways engage in extensive interactions in the nervous system (Long et al., 2009). However, to date there are no published reports on reinforcing/rewarding effects of drugs that selectively increase 2-AG levels in the brain, like MAGL inhibitors, or dual FAAH/MAGL inhibitors, which increase levels of both 2-AG and anandamide.

The present study shows that the endocannabinoid 2-AG functions as a positive reinforcer in monkeys with or without a cannabinoid self-administration history and that its reinforcing effects are mediated by cannabinoid $\mathrm{CB}_{1}$ receptors. Thus, intravenous self-administration of 2-AG by squirrel monkeys provides a valuable procedure for studying the abuse liability of medications that interfere with brain 2-AG signaling and for investigating mechanisms involved in the reinforcing effects of endocannabinoids.

\section{References}

Abadji V, Lin S, Taha G, Griffin G, Stevenson LA, Pertwee RG, Makriyannis A (1994) (R)-methanandamide: a chiral novel anandamide possessing higher potency and metabolic stability. J Med Chem 37:1889-1893.

Agurell S, Halldin M, Lindgren JE, Ohlsson A, Widman M, Gillespie H, Hollister L (1986) Pharmacokinetics and metabolism of delta 1-tetrahydrocannabinol and other cannabinoids with emphasis on man. Pharmacol Rev 38:21-43.

Beltramo M, Piomelli D (2000) Carrier-mediated transport and enzymatic hydrolysis of the endogenous cannabinoid 2-arachidonylglycerol. Neuroreport 11:1231-1235.

Bisogno T, Berrendero F, Ambrosino G, Cebeira M, Ramos JA, FernandezRuiz JJ, Di Marzo V (1999) Brain regional distribution of endocannabinoids: implications for their biosynthesis and biological function. Biochem Biophys Res Commun 256:377-380.

Caillé S, Alvarez-Jaimes L, Polis I, Stouffer DG, Parsons LH (2007) Specific alterations of extracellular endocannabinoid levels in the nucleus accumbens by ethanol, heroin, and cocaine self-administration. J Neurosci 27:3695-3702.

Di Marzo V, Berrendero F, Bisogno T, González S, Cavaliere P, Romero J, Cebeira M, Ramos JA, Fernández-Ruiz JJ (2000) Enhancement of anandamide formation in the limbic forebrain and reduction of endocannabinoid contents in the striatum of delta9-tetrahydrocannabinol-tolerant rats. J Neurochem 74:1627-1635.

Dinh TP, Carpenter D, Leslie FM, Freund TF, Katona I, Sensi SL, Kathuria S, Piomelli D (2002) Brain monoglyceride lipase participating in endocannabinoid inactivation. Proc Natl Acad Sci U S A 99:10819-10824.

Gonsiorek W, Lunn C, Fan X, Narula S, Lundell D, Hipkin RW (2000) Endocannabinoid 2-arachidonyl glycerol is a full agonist through human type 2 cannabinoid receptor: antagonism by anandamide. Mol Pharmacol 57:1045-1050.

González S, Cascio MG, Fernández-Ruiz J, Fezza F, Di Marzo V, Ramos JA (2002) Changes in endocannabinoid contents in the brain of rats chronically exposed to nicotine, ethanol or cocaine. Brain Res 954:73-81.

Justinova Z, Tanda G, Redhi GH, Goldberg SR (2003) Self-administration of Delta(9)-tetrahydrocannabinol (THC) by drug naive squirrel monkeys. Psychopharmacology (Berl) 169:135-140.

Justinova Z, Solinas M, Tanda G, Redhi GH, Goldberg SR (2005) The endogenous cannabinoid anandamide and its synthetic analog $\mathrm{R}(+)$ methanandamide are intravenously self-administered by squirrel monkeys. J Neurosci 25:5645-5650.

Justinova Z, Mangieri RA, Bortolato M, Chefer SI, Mukhin AG, Clapper JR, King AR, Redhi GH, Yasar S, Piomelli D, Goldberg SR (2008) Fatty acid amide hydrolase inhibition heightens anandamide signaling without producing reinforcing effects in primates. Biol Psychiatry 64:930-937. 
Katona I, Freund TF (2008) Endocannabinoid signaling as a synaptic circuit breaker in neurological disease. Nat Med 14:923-930.

Ko MC, Terner J, Hursh S, Woods JH, Winger G (2002) Relative reinforcing effects of three opioids with different durations of action. J Pharmacol Exp Ther 301:698-704.

Long JZ, Nomura DK, Vann RE, Walentiny DM, Booker L, Jin X, Burston JJ, Sim-Selley LJ, Lichtman AH, Wiley JL, Cravatt BF (2009) Dual blockade of FAAH and MAGL identifies behavioral processes regulated by endocannabinoid crosstalk in vivo. Proc Natl Acad Sci U S A 106:20270-20275.

Mackie K, Devane WA, Hille B (1993) Anandamide, an endogenous cannabinoid, inhibits calcium currents as a partial agonist in N18 neuroblastoma cells. Mol Pharmacol 44:498-503.

Mechoulam R, Ben-Shabat S, Hanus L, Ligumsky M, Kaminski NE, Schatz AR, Gopher A, Almog S, Martin BR, Compton DR (1995) Identification of an endogenous 2-monoglyceride, present in canine gut, that binds to cannabinoid receptors. Biochem Pharmacol 50:83-90.

Minkkilä A, Saario S, Nevalainen T (2010) Discovery and development of endocannabinoid-hydrolyzing enzyme inhibitors. Curr Top Med Chem 10:828-858.

Pertwee RG (2008) Ligands that target cannabinoid receptors in the brain: from THC to anandamide and beyond. Addict Biol 13:147-159.

Petrosino S, Di Marzo V (2010) FAAH and MAGL inhibitors: therapeutic opportunities from regulating endocannabinoid levels. Curr Opin Investig Drugs 11:51-62.

Piomelli D (2005) The endocannabinoid system: a drug discovery perspective. Curr Opin Investig Drugs 6:672-679.

Savinainen JR, Järvinen T, Laine K, Laitinen JT (2001) Despite substantial degradation, 2-arachidonoylglycerol is a potent full efficacy agonist mediating $\mathrm{CB}(1)$ receptor-dependent G-protein activation in rat cerebellar membranes. Br J Pharmacol 134:664-672.
Scherma M, Panlilio LV, Fadda P, Fattore L, Gamaleddin I, Le Foll B, Justinová Z, Mikics E, Haller J, Medalie J, Stroik J, Barnes C, Yasar S, Tanda G, Piomelli D, Fratta W, Goldberg SR (2008) Inhibition of anandamide hydrolysis by cyclohexyl carbamic acid 3' -carbamoyl-3-yl ester (URB597) reverses abuse-related behavioral and neurochemical effects of nicotine in rats. J Pharmacol Exp Ther 327:482-490.

Schlosburg JE, Blankman JL, Long JZ, Nomura DK, Pan B, Kinsey SG, Nguyen PT, Ramesh D, Booker L, Burston JJ, Thomas EA, Selley DE, Sim-Selley LJ, Liu QS, Lichtman AH, Cravatt BF (2010) Chronic monoacylglycerol lipase blockade causes functional antagonism of the endocannabinoid system. Nat Neurosci 13:1113-1119.

Sugiura T, Kondo S, Sukagawa A, Nakane S, Shinoda A, Itoh K, Yamashita A, Waku K (1995) 2-Arachidonoylglycerol: a possible endogenous cannabinoid receptor ligand in brain. Biochem Biophys Res Commun 215:89-97.

Sugiura T, Kishimoto S, Oka S, Gokoh M (2006) Biochemistry, pharmacology and physiology of 2-arachidonoylglycerol, an endogenous cannabinoid receptor ligand. Prog Lipid Res 45:405-446.

Tanda G, Munzar P, Goldberg SR (2000) Self-administration behavior is maintained by the psychoactive ingredient of marijuana in squirrel monkeys. Nat Neurosci 3:1073-1074.

Tanimura A, Yamazaki M, Hashimotodani Y, Uchigashima M, Kawata S, Abe M, Kita Y, Hashimoto K, Shimizu T, Watanabe M, Sakimura K, Kano M (2010) The endocannabinoid 2-arachidonoylglycerol produced by diacylglycerol lipase alpha mediates retrograde suppression of synaptic transmission. Neuron 65:320-327.

Viganò D, Grazia Cascio M, Rubino T, Fezza F, Vaccani A, Di Marzo V, Parolaro D (2003) Chronic morphine modulates the contents of the endocannabinoid, 2-arachidonoyl glycerol, in rat brain. Neuropsychopharmacology 28:1160-1167. 